\title{
The influence of online problem-based learning on teachers' professional practice and identity
}

\author{
Steve Wheeler*, Peter Kelly and Ken Gale \\ University of Plymouth, UK
}

In this paper we describe the design of a managed learning environment called MTutor, which is used to teach an online Masters Module for teachers. In describing the design of MTutor pedagogic issues of problem-based learning, situated cognition and ill-structured problems are discussed. MTutor presents teachers with complex real-life teaching problems, which they are required to solve online through collaboration with other teachers. In order to explore the influence of this online learning experience on the identity and practice of teachers, we present the results from a small-scale study in which six students were interviewed about their online experiences. We conclude that, within the sample, students' engagement with online problem-based learning within their community of practice positively influenced their professional practice styles, but that there is little evidence to suggest that online identity influences real-life practice.

\section{Introduction}

The University of Plymouth's Integrated Masters Module Programme draws clients from primary and secondary schools, further education colleges, the National Health Service, the military and the prison service. Most Integrated Masters Module Programme students work full time and are distributed across a large geographical area, so module delivery must be flexible. The 'Information and Communication Technology: Theoretical Perspectives' module was designed with these needs in mind, and is delivered through a managed learning environment in a hybrid blend. Blended delivery is through face-to-face teaching and learning (lectures, seminars, group work and discussion), online delivery (electronic resources, threaded discussion, problem-based learning [PBL] scenarios and online multiple response question

\footnotetext{
*Corresponding author. Faculty of Education, University of Plymouth, Drake Circus, Plymouth PL4 8AA, UK. Email: steve.wheeler@plymouth.ac.uk
} 
assessment), videoconferencing and distance tutorial support (synchronous via telephone, asynchronous via email).

The online element of the module is presented in a problem-based format, where students immerse themselves within situated aspects of the theory such as 'real purpose tasks' and transformed teacher roles (Jonassen, 1996). Strategic videoconference sessions are interspersed throughout the module to introduce forthcoming tutorials and consolidate previous tutorials. Using this blend of delivery methods, the module offers dispersed student groups a dynamic and discursive environment within which to explore and discuss course materials.

\section{Underpinning design principles of MTutor}

The managed learning environment used to deliver the 'Information and Communication Technology: Theoretical Perspectives' module is called MTutor. It was designed to be used as a 'Mindtool' rather than as 'shovelware'. Many lecturers transfer their course notes and learning resources over to webpages and erroneously expect students to use them with no tutorial support (Forsyth, 2001). This practice has been scathingly labelled as 'shovelware', a practice that has contributed to a growing discontent with online teaching methods. Jonassen et al. (1999), however, call for the computer to be used as a 'mindtool' to promote open-ended learning. The mindtools approach challenges the established 'computer-based learning approach' where knowledge resided in the machine and was systematically delivered to the student. Instead, students bring their knowledge to the computer, which provides a sort of 'mental gymnasium' within which the student can 'workout' to build new knowledge through proactive exploration and collaboration with others. MTutor performs these mindtool functions, by providing the remote student with a combination of meaningful, open-ended learning experiences in a flexible, non-linear environment.

MTutor hosts a threaded discussion group facility and a range of multiple-choice and multiple-response question options. MTutor has been successfully used to offer modules in health studies, engineering and psychology (Culverhouse \& Burton, 1998, 2001), although each of these was implemented within a networked on-campus based environment. In our context, MTutor is used for the first time as a platform for online distance learning, with an emphasis on PBL.

\section{Problem-based learning}

PBL methods were first developed to address the difficulties inherent in conventional teaching and learning (Barrows, 2002), and serve to facilitate deeper levels of cognitive engagement. PBL strongly promotes the development of skills through the use of complex, real-life problems and motivates students to adopt deeper approaches to study (Duch et al., 2001), promoting critical thinking, collaborative learning, verbal and written communication skills and lifelong learning skills. The power of PBL lies in its facility to present learners with authentic problems they might encounter in the 'real world'. Students must also practice problem-solving skills while reading more 
widely and investigating more deeply the structure and context of the presented problem. PBL tutors tend to act as guides and facilitators in the process, and may even adopt a learning role themselves (Roblyer et al., 1997).

Online PBL is sometimes referred to as distributed PBL and is a version of PBL that is useful to students who are separated from their tutors by distance. Learning is mediated through online technologies within a shared, 'virtual' distributed learning environment. This distributed community of practice (Wenger, 1998) encourages a self-regulating and autonomous body of students. Lave and Wenger's (1991) notion of 'communities of practice' is based upon the idea that learning involves a deepening process of participation in a social group over a period of time. They use the related notions of 'legitimate peripheral participation' and 'situated learning' to explain the way in which learners move from the margins of a group, gradually approximating to its core, and associate this movement with learning. The 'communities of practice' model was applied to the development of the online module.

At the start of the module, students are encouraged to collaborate as a team with each monitoring the progress of others while at the same time assessing their own (Barrows, 2002). Online collaborative knowledge building approaches have previously been used to promote effective learning in inservice teacher training (Ahlberg et al., 2001) and to establish communities of practice in computer-mediated communication-based initial teacher training (Clarke, 2002; Tsui \& Ki, 2002).

\section{Situated cognition}

We define PBL as learning based on the 'thinking through' of real-life problems or, more precisely, situated cognition. Of course, everyday problems are rarely clear cut in nature, as many have no structure and may bear no similarities to previously encountered problems. Problem-solving is arguably one of the most important skills any student can acquire, as it enables generalisability across diverse problems. We encounter problems every day, some of which merely take a minute or two to solve. Others take days, weeks or even years to circumvent, and then often with no guarantee of success. Problem-solving should therefore be viewed not as a product, but as a key component of the lifelong learning process, drawing on many cognitive resources and requiring much commitment and practice. In our view the effective representation of problems is best achieved in a situated context, and for teachers operating within a community of practice this is crucial. To emulate real-life teaching situations, problems can be constructed that have more than one possible solution, and with limited information to solve them. We refer to this form of situated mindtool as the 'ill structured problem'.

\section{Ill-structured problems}

Presenting students with ill-structured problems has a number of pedagogical advantages. Simon (1973) shows that because they are primarily representative of 
real-life situations they have practical applications, and argues that ill-structured problems exhibit three key characteristics. First, they exhibit greater complexity and have less definite criteria for determining when the problem has been solved. Second, not all the information has been provided in the presentation of the problem, leaving several gaps for the learner to fill in. Finally, ill-structured problems have no apparent 'rules' that can be immediately applied (Simon, 1978). It is also conceivable that ill-structured problems offer better generalisability potential across diverse problem types. However, the extent to which a problem is ill-structured may depend upon the skills and knowledge that the learner brings to bear on the problem.

Learners with the requisite knowledge may perceive a problem to be better defined than those with no, or little, knowledge (Frederiksen, 1984). Moreover, studentcentred learning can be supported using ill-structured problem-solving. For example, ill-structured problems tend to encourage learners to define the problem themselves (Kahney, 1994). This leads in turn to greater motivation through ownership and, ultimately, the construction of personal meaning within individualised professional practice contexts. Ill-structured problems, then, are useful to present to groups of students who have differing levels of experience and knowledge, making for a diverse community of practice.

Within the structure of the online module are four tutorials, each of which presents the student with an ill-structured problem for them to consider. In our module, the first problem-based scenario, for example, takes the form of a heated debate between two teachers in the staff room. One teacher is opposed to the use of computers across the curriculum, while the other is a strong advocate. This polemic is analysed by the students, and a range of theoretical and practical issues can be teased out which they later discuss online and during the videoconferences within their community, which includes their peers and the module tutors.

\section{The influence of online learning on professional practice and identity}

In PBL, each student will generally abstract the meaning he/she feels to be uppermost both from an examination of the problem space and in the presented dialogue, and this will invariably be an issue or set of issues that impact upon his/ her own professional practice in some way. Some students may recognise elements of their own professional practice represented in the PBL scenarios, or may identify the attitudes or beliefs of their colleagues from, say, a dialogue around the problem. Discussion of these issues often brings about a greater sense of self-awareness and a deeper examination of one's own professional practices and mores, leading to a challenge on professional identity. Professional identity is the teacher's representation of the self within the context of professional practice. It emerges from an iterative process of reflection on practice through continual evaluation of performance. It can be argued that, in online environments, professional identity can be shaped and influenced most keenly through engagement within mediated discussion groups. 
The argumentative nature of the ensuing online rhetoric encourages each student to challenge and further construct, deconstruct and reconstruct their own personal sense of meaning from the problem and its implications. This reflective process should have an impact upon the professional identity each is in the process of forming and reforming, challenging their assumptions and modifying their images of the self in a professional context.

Furthermore, the discursive dialogue that takes place can in itself create a zone of proximal development (ZPD). The ZPD represents the extent to which a learner can acquire skills and knowledge, given the support of a more knowledgeable peer (Vygotsky, 1962, 1978). Thus, for each learner and over a period of time, a mutual support climate is developed as the learner's cognitive development is incrementally shifted through a process of negotiation through peer dialogue. The ZPD tends to be variable, based upon the context of each problem and the extent to which each student possesses the skills, knowledge and attitude to support peers or be supported. Baron and Misovich (1993) claim that the Vygotskian ideal of the ZPD can be extended to encompass a group-mediated 'zone of proximal change'.

We can connect the notion of ZPD and the 'scaffolding' of learning to that of a community of practice, where learning is linked to the facilitative practices associated with working with colleagues, peers and tutors. The kind of learning proposed by Lave and Wenger (1991) is not necessarily a narrow cognitive notion of learning or the simple acquisition of skills. Rather, it is a kind of collective learning organised around some particular area of knowledge and activity giving members a sense of joint enterprise and identity. For a community of practice to function it needs to generate a shared repertoire of ideas, commitments and memories. It also needs to develop various resources such as tools, documents, routines, vocabulary and symbols that in some way carry the accumulated knowledge of the community. In the online module, the online discussion and videoconferencing are used as mindtools to facilitate these activities.

It is possible that synchronous mindtools such as videoconferencing may provide more immediacy for social exchange that their asynchronous counterparts. Humans are social beings who depend upon feedback from their peers to validate their own beliefs (Jonassen, 1998) and online discussions, both synchronous and asynchronous, are fertile environments within which this kind of self-examination of identity can be propagated.

Increased awareness of online learning has been accompanied by the need for teachers to understand the potential for changes in identity and also the ability to switch identities in different contexts. Students enrolling for the online module tend to be acutely aware of their practice styles and professional identity as many have several years of teaching experience. However, those who are naïve to the use of electronic communications media are unaware of what might constitute their online identity. Turkle (1997) suggests that online identity is often different to 'real-life' identity, and that the online personae can change according to the context of the online experience. Although Turkle's commentary was descriptive of the online gaming scene, we believe it to be equally applicable to online learning. 


\section{The case study}

MTutor presents teachers with complex real-life teaching problems, which they are required to solve online through collaboration with other teachers. We were interested in exploring the influence of this online learning experience on identity and professional practice. We therefore conducted a small-scale study to try and answer the following questions:

- To what extent do the online learners develop different identities to manage their online identity in comparison with their everyday 'real-life' identities?

- Do the online experiences of teachers impact upon their 'real world' style of professional practice and does changing identities have any influence?

A semi-structured interview schedule was created to address the issues that the three research team members agreed to be salient to the research questions. A small group of six students who had recently completed the online module as a whole cohort were recruited by email for the study.

As two of the authors had previously tutored on the course, a research assistant unknown to the group individually interviewed each student. Each of the interviews lasted between 30 and 60 minutes. The tape recordings of the interviews were transcribed and then the content of their responses was analysed by the research team. Questions focused on individual encounters with the online module, asking each participant to reflect in particular on their experiences studying online, their online and 'real-life' identities, and also any changes in their professional practice styles. Participants were also encouraged to elaborate within the schedule of questions.

\section{Analysis and discussion}

The six students in this case study had a range of backgrounds and experiences:

- Student 1: Was a primary school teacher, has a B.Ed. degree, and now teaches Initial Teacher Training (ITT) in the Faculty of Education at the University of Plymouth. He is in his early 40s.

- Student 2: Is a civilian educator teaching Adult Basic Skills, within the Prison service. He has a B.A. degree and is in his mid 40s.

- Student 3: Was previously a service engineer and now teaches information and communication technology (ICT) as a part-time lecturer in the Faculty of Education. He is working towards his first degree, having obtained a Cert. Ed. He is in his late 30 s.

- Student 4: Is a teaching assistant working within a primary school, she is working towards her first degree after obtaining her Cert. Ed. She is in her mid 50s.

- Student 5: Is a primary school teacher specialising in ICT and has a first degree (B.Ed.). She is in her late 30s.

- Student 6: Was a primary teacher and now works as a research assistant at the University of Plymouth. He has a bachelor's degree, two Masters degrees and a postgraduate teaching qualification, specialising in Geography. He is in his mid 30s. 
In order to answer the questions posed in this small-scale study and explore the issues of identity and professional practice, the results from each student will be summarised and presented.

\section{Changes in identity}

Student 1 , who had been a primary school teacher and now works in higher education, reported that his online identity was 'the same person as face to face'. However, he detected that the group's online identity was subtly different to a reallife, face-to-face student group. He acknowledged that although the group 'shared the same problems, [went through] the same process, [and] were on the same course', he was unsure what actually prompted the identity of other group members, as for most of the module they were only encountered through electronic media such as the online discussion group. He was uncertain whether group identity online was derived from 'the thoughts they put forward, the style of writing or the way [they] respond to messages'. Although he was certain that his online identity was identical to his real-life identity, he expressed uncertainty about the validity of the identity of others.

Student 2, another male student who teaches in adult education, shared the opinion of student 1 in that ' $\ldots$ online I am not usually different from my real persona'. He saw identity change as somewhat of a moral dilemma, stating that 'in a way it is lying if you take on a different persona'. He admitted, however, that there were occasions in mediated environments when he modified his identity, most usually when he encountered 'someone who doesn't know me. I enjoy an argument. I will start an argument. It is always an interesting situation'. However, he conceded 'I would do that in a real life situation as well though'. This student presented a fairly defined personal identity and sustained it throughout the duration of the module. His real-life practice does not appear to have been acutely influenced by any identity changes in the online environment.

Student 3, another male teacher working in higher education, was also of the opinion that he changed little when in an online environment. He argued that online he was '... very much the same as I am face to face'. He revealed that when he first experienced the online world, he operated in a strictly formalised manner, and was careful to send emails and discussion group messages that were correctly punctuated with errors corrected. He also reported that he typed his messages in a very formal style and that this reflected his real-life identity. He admitted, however, that there were 'all sorts of selves', depending on the different contexts of real life. This indicates that he was carefully negotiating his way through a strictly self-imposed ZPD, where he ensured that he carefully managed his impression. He commented that regardless of all the possible 'selves', 'I don't have a different identity online. I don't mask me. If they read me online they will recognise me'. Interestingly, there is an assumption within this statement that other online individuals would already 'know' him, which in online environments of course, is rarely the case. Regardless of this student's sense of continuation of identity, he remained on the periphery of the community of 
practice, and was reluctant to engage with others online. Instead, he preferred to communicate via the videoconference links with the rest of the group, where, comfortable within his own ZPD, he was able to make several valuable contributions.

Student 4, a female teacher working in primary education, differed significantly in her views of online identity. She considered herself to be 'calmer, more reasonable and intelligent' than she was in real life. 'I used to let my frustration and need for speed spill over', she reported, 'and this course has taught me it is not needed'. In contrast to Student 3, this student seemed to have been aided by the affordance of asynchronous online discussion, with its time to reflect and the slowly building permanence of the message archive seen as contributing toward a positive experience. She claimed to have become 'better and more confident' as a result of the online discussion experience, yet also felt a little excluded from the learning community. Instead she stated that 'it was easier to tell myself I was interacting with a machine rather than with a group of people'. This was evidenced by regular postings to the online discussions, but less engagement in the videoconferenced discussions than her peers. Even though she reported the experience to be positive in terms of shaping her personal style, she nevertheless perceived a sense of alienation from the rest of the group and during synchronous interaction remained on the periphery of the community. It is not known what factors may have caused this, but we can speculate that student 4's personal ZPD could be located within the more anonymous text-based interaction mode.

Student 5, another female teacher working in primary education, claimed that her identity was very similar online and in real life. However, she admitted that there were times when she slipped between identities, confessing that 'I like to be seen as clever', but 'then I would be laughing and giggling and selling myself short to not be seen as clever.' Student 5 engaged with the videoconferenced discussion sessions and made many useful contributions, but tended to see her online contributions as trivial. 'I was reading [my contributions] back on the discussion board and just cringing. Like so and so has a theory, and I'll go, I do agree ... I seem to be quite insubstantial ...'. She also reported that she did not feel like a member of the group, and that confusion of the identity of other students online helped to contribute to this alienation. For Student 5, progress was hampered due to lack of knowledge of the character of her community of practice, something she viewed as an artefact of the mediated environment. She thought that the online message boards actually thwarted discussion: 'There wasn't much engagement really. If you kind of answered every discussion board [topic], not everyone did, if you did five comments, normally in a tutorial you would say more than five things.' She evaluates the online discussion in terms of quantity due to the brevity of the actual contributions, an indication that her preferred ZPD is located within a more immediate and face-to-face mode of interaction where richer social cues might be more forthcoming.

Finally, Student 6, a male primary teacher now working in higher education, revealed some disparity between his online and real-life identities. He reported that his online identity was 'secretive perhaps, nervous I think. Lacking self confidence'. 
However, when asked what kind of a teacher he was, he stated that he was '... quite outgoing, humorous, observant ...'. When asked about his study routine he said: 'I worked in isolation really...', rarely discussing his progress with other module students. Student 6 enjoyed the online learning, but preferred discussion with his peers through the videoconference links. He said: 'I got much more sense of group through the videoconferencing. I hadn't done it before, and I was quite apprehensive and it was quite a strange feeling but I believe we got more of a sense of group dynamic than on the message board', and he later stated that he 'took an active role in the videoconferencing. It may have given me more of a feeling of being a part of a group. Made me more involved and may then have made a more prominent part'. For student 6 , a 'sense of group' was an important aspect of the learning process, motivating him to contribute, shaping his identity as a learner and providing a deeper and more meaningful level of social support. Student 6's ZPD is located across all modes of interaction, enabling him to deeply participate as a member of his community of practice.

For almost all of the students in this small sample, online identity is reported to be similar or identical to real-life identity. However, as tutors we detected small changes in identity from some as the module progressed but can only speculate to what these changes may be attributed. For example, when online there is evidence that students may 'manage their impression' a little more formally than in real-life contexts, and this may equally be the result of self-confidence or a lack of the same. Most reported that the mediated learning experience helped them to reflect upon their own professional practice and for some may even have challenged their current practices. This effect, however, may result more from the discussions and the PBL materials than from the medium used to convey them.

\section{Changes in practice style}

All the students reported changes in professional practice style as a result of the online module. Student 1 reported that he now had a greater awareness of how to enable his pupils to interact with children in other countries. He reported that due to his own experiences working with ill-structured problems, he now 'would like to give them a chance to be in the system but look outside the system so they can change it eventually to make it better'. Student 1 therefore saw problem-based scenarios as empowering and liberating for learners, and was attempting to introduce them into his own teaching.

Student 2 admitted that he was 'certainly not at the end of that change' in his professional development, but had formed the opinion that 'there are pros and cons to computer teaching, and I am a little but cynical. I see a huge danger that we could automate learning and this could be negative'. His views of computer-based learning have become entrenched, as he has examined his own views and professional practice, but he has emerged with a balanced perspective of the inherent benefits and limitations of online learning and emphasises the value he places on student centred learning. 
Student 3 also valued student-centred approaches and modified his resource development as a result of his experiences on the module. He reported that 'Originally my online resources tended to be informative and information based. Now I have ideas of it being more student centred'. When asked for a specific example of his practice style change Student 3 said that 'previously I would have explained to students in a theoretical way. It would have been very much how theorists see it. My idea is now more experienced based. I get the student to experience for themselves what it is like ...' This shift in values directly reflected Student 3's own engagement in PBL, and is a facet that he genuinely appeared to value. He reported that he now creates more interactive materials that provide his students with choices and reflective tasks, to develop their thinking skills.

Student 4 reports she derived much personal satisfaction from her experience on the module. Her self-confidence improved and she stated that 'I can do this, I have the ability and I am hoping other people will see this happening and think "she can do this, I can do this"'. She feels that her new found confidence can be imparted to her colleagues and that, in this way, the entire school will benefit and their computerbased activities will be enhanced.

A different aspect emerged for Student 5, who was inspired from the module to act as a change agent in her school. She reported that 'We have got two interactive whiteboards at school and one has been put into a teacher's class who didn't really want it and no-one in the school wanted it ...'. She goes on to describe her strategy for embedding the interactive whiteboards into everyday school use. Working with the headteacher she has devised an induction programme: 'there is only 4 staff at school so I will spend time with each of them ...'. She feels that her self-esteem has also been raised as a result of her experiences studying on the module and that this has benefited her professionally: '... so I gained self esteem, gained by having something different and professionally it has changed me'. Student 5 recounted a conversation with her head teacher who was discussing strategies for improving ICT use in the school: '...we must do something with laptops', she advised him, 'because research has shown laptops make a big difference to teacher motivation. I thought-I wouldn't have known that before'.

Finally, student 6 who is in his first year of teaching in higher education, reported several major changes in his professional practice style as a result of the content of the online module. When asked if there were any changes made in his teaching he said: 'Yes, a lot. I used a lot of the theoretical aspects. This has helped to underpin a lot of the courses I have to run'. Two of the courses Student 6 was teaching on were new to him, but he has reported that some of the theoretical aspects of the module have been invaluable in helping him to conceptualise delivery of new courses in initial teacher training.

\section{Student evaluations of MTutor}

During the interviews with the six students, interesting information emerged regarding their evaluation of and satisfaction with their online learning experience. For some, 
flexibility was an important affordance of the online PBL. For example, Student 6 suggested that 'it was useful being able to turn the computer on and read something for twenty minutes or so'. Student 5 concurred that flexibility was an important facet of the module's success, 'in that you kind of had the flexibility of the computer combined with being able to get to know [the tutor] in the flesh'. The blended mode of delivery was seen to be powerful by others, as according to Student 2 'the purpose of the communication will affect the means you use'. Face-to-face, videoconference and online discussion, he reported, 'are all means of communication. If you need to speak to someone quickly you pick up the telephone ... You use e-mail to ask a question generally ... if you want to discuss a problem you go and speak face to face'.

Notwithstanding, for most of the students, once the novelty value and anxiety effects had been overcome, the synchronous nature of videoconferencing was preferred to the online discussion group as a means of comparison, debate and collaboration. Online message boards have a permanency, as well as the time-shifted effect of imposing a waiting time for responses, and this may for some have inhibited fuller participation within the community of practice. Moreover, a group of six students may not offer a critical mass of group dynamic required for meaningful discussion within electronic environments of this kind. It is possible that small groups may be better served with synchronous discussion such as videoconferencing, while larger groups may gain a more meaningful learning experience through asynchronous media, as contributions can be made in a more equitable setting. Managed learning environment designers should therefore consider whether the choice of technology will be a help or a hindrance to good learning outcomes (Wheeler, 2000).

\section{Conclusions}

We could claim that changes in practice style were a direct result of engagement with online PBL but this would be contentious, because it is impossible to state whether changes would have occurred anyway, regardless of each student's participation on the module. Furthermore, we do not know whether online learning, or the problembased elements, or some other factor has influenced changes in practice. However, there is evidence that the online students found the PBL content of the module to be deeply engaging and one that challenged their own professional practice styles. They became convinced that they could use the same problem-based methods to support their own students. Some also considered this to be a move closer to student-centred teaching.

Students were very positive about the way in which course materials were presented online using PBL, but some criticised the nature of the online discussion, claiming that it prohibited rather than liberated discussion. We can speculate that several factors may have influenced this outcome, including lack of familiarity or confidence of use, the permanency of the message archive (students not able to retract what they had written once it was posted), asynchronous aspects such as the need to wait for responses, and a time disparity of use due to the quicker students reaching the message board long before the slower students. All of these factors should be 
considered by those who wish to build asynchronous discussion facilities into the design of managed learning environments.

It is not possible to evaluate how any other presentation of the same content may have been received, as this was not a comparative study. However, some students reported that their confidence was boosted-an affective outcome that positively influenced their professional practice-which may have arisen from the extended time they had spent negotiating meaning within their small online community of practice.

Baron and Misovich's notion of a group-mediated 'zone of proximal change' may have been in evidence, particularly during the videoconference sessions. Students reported that they gained more by debating the problems using the visual medium than they did through online text-based discussion, a phenomenon evidenced by the reticence of some to engage in meaningful discussion through the message board. This raises questions over the efficacy of asynchronous technologies to mediate dialogue for small groups.

It is difficult to claim causal links between online identity and professional practice in the 'real world' due to the small-scale qualitative nature of this study. A more quantitative, larger scale study would be required to enable us to establish any causal evidence. Yet this small-scale study has served to highlight some interesting features of online PBL and the nature of online communities of practice. Teachers tend to become convinced of the efficacy of the higher cognitive level of engagement PBL yields, and often change their style to accommodate it into their own professional practice. Furthermore, mature, full-time professionals prefer the flexibility that online learning affords, often in spite of the many accompanying problems and issues.

Finally, it is worth acknowledging that while distributed PBL is a reworking of established case-based learning, it is as yet a nascent online method, mediated by technologies that are still unfamiliar to many. As has already been indicated, the opportunity exists to further examine the effectiveness of online or distributed PBL; its place specifically in postgraduate studies and generally within the practice of distance education.

\section{References}

Ahlberg, M., Kaasinen, A., Kaivola, T. \& Houtsonen, L. (2001) Collaborative knowledge building to promote in-service teacher training in environmental education, Technology, Pedagogy and Education, 10(3), 227-238.

Baron, R. M. \& Misovich, S. J. (1993) An integration of Gibsonian and Vygotskian perspectives on changing attitudes in group contexts, British fournal of Social Psychology, 32, 53-70.

Barrows, H. (2002) Is it truly possible to have such a thing as dPBL?, Distance Education, 23(1), $119-122$.

Clarke, L. (2002) Putting the 'C' in ICT: using computer conferencing to foster a community of practice among student teachers, Technology, Pedagogy and Education, 11(2), 163-180.

Culverhouse, P. F. \& Burton, C. J. (1998) MTUTOR—a tutorial shell for supporting problem solving, paper presented at the Bringing Information Technology to Education (BITE) Conference, Maastricht, 25-27 March. 
Culverhouse, P. F. \& Burton, C. J. (2001) Learning best-practice in design and problem skill development: Mtutor-a web based distance learning tool, Quarterly Review of Distance Education, 2(3), 221-232.

Duch, B. J., Groh, S. E. \& Allen, D. E. (2001) The power of problem based learning (Stirling, VA, Stylus).

Forsyth, I. (2001) Teaching and learning materials \& the internet (London, Kogan Page).

Frederiksen, N. (1984) Implications of cognitive theory for instruction in problem solving, Review of Educational Research, 54(3), 363-407.

Jonassen, D. H. (1996) Computers in the classroom: mindtools for critical thinking (Englewood Cliffs, NJ, Prentice Hall).

Jonassen, D. H. (1998) Designing constructivist learning environments, in: C. M. Reigeluth (Ed.) Instructional design theories and models: their current state of the art (2nd edn) (Mahwah NJ, Lawrence Erlbaum Associates).

Jonassen, D. H., Peck, K. L. \& Wilson, R. G. (1999) Learning with technology: a constructivist perspective (Columbus, $\mathrm{OH}$, Merill Prentice Hall).

Kahney, H. (1994) Problem solving: current issues (2nd edn) (Buckingham, Open University Press).

Lave, J. \& Wenger, E. (1991) Situated learning. Legitimate peripheral participation (Cambridge, University of Cambridge Press).

Roblyer, M. D., Edwards, J. \& Havriluk, D. M. (1997) Integrating educational technology into teaching (Upper Saddle River, NJ, Prentice Hall).

Simon, H. A. (1973) The structure of ill-structured problems, Artificial Intelligence, 4, 181-201.

Simon, H. A. (1978) Information processing theory of human problem solving, in: W. K. Estes

(Ed.) Handbook of learning and cognitive processes, Volume 5. Human information processing (Hillsdale NJ, Erlbaum).

Tsui, A. B. M. \& Ki, W. W. (2002) Teacher participation in computer conferencing: sociopsychological dimensions, Technology, Pedagogy and Education, 11(1), 23-44.

Turkle, S. (1997) Life on screen: identity in the age of the internet (New York, Simon \& Shuster).

Vygotsky, L. S. (1962) Thought and language (Cambridge, MA, Harvard University Press).

Vygotsky, L. S. (1978) Mind in society (Cambridge, MA, Harvard University Press).

Wenger, E. (1998) Communities of practice, learning, meaning and identity (Cambridge, Cambridge University Press).

Wheeler, S. (2000) Instructional design in distance learning through telematics. Quarterly Review of Distance Education, 1(1), 31-44. 